\title{
Evaluating the streamflow simulation capability of PERSIANN-CDR daily rainfall products in two river basins on the Tibetan Plateau
}

\author{
Xiaomang Liu ${ }^{1,2}$, Tiantian Yang ${ }^{2}$, Koulin $\mathrm{Hsu}^{2}$, Changming Liu ${ }^{1}$, and Soroosh Sorooshian ${ }^{2}$ \\ ${ }^{1}$ Key Laboratory of Water Cycle \& Related Land Surface Process, Institute of Geographic Sciences and \\ Natural Resources Research, Chinese Academy of Sciences, 100101 Beijing, China \\ ${ }^{2}$ Department of Civil and Environmental Engineering, University of California, Irvine, California, USA \\ Correspondence to: Tiantian Yang (tiantiay@uci.edu)
}

Received: 3 June 2016 - Published in Hydrol. Earth Syst. Sci. Discuss.: 23 June 2016

Revised: 10 December 2016 - Accepted: 20 December 2016 - Published: 10 January 2017

\begin{abstract}
On the Tibetan Plateau, the limited groundbased rainfall information owing to a harsh environment has brought great challenges to hydrological studies. Satellitebased rainfall products, which allow for a better coverage than both radar network and rain gauges on the Tibetan Plateau, can be suitable alternatives for studies on investigating the hydrological processes and climate change. In this study, a newly developed daily satellite-based precipitation product, termed Precipitation Estimation from Remotely Sensed Information Using Artificial Neural Networks - Climate Data Record (PERSIANN-CDR), is used as input for a hydrologic model to simulate streamflow in the upper Yellow and Yangtze River basins on the Tibetan Plateau. The results show that the simulated streamflows using PERSIANN-CDR precipitation and the Global Land Data Assimilation System (GLDAS) precipitation are closer to observation than that using limited gauge-based precipitation interpolation in the upper Yangtze River basin. The simulated streamflow using gauge-based precipitation are higher than the streamflow observation during the wet season. In the upper Yellow River basin, gauge-based precipitation, GLDAS precipitation, and PERSIANN-CDR precipitation have similar good performance in simulating streamflow. The evaluation of streamflow simulation capability in this study partly indicates that the PERSIANN-CDR rainfall product has good potential to be a reliable dataset and an alternative information source of a limited gauge network for conducting long-term hydrological and climate studies on the Tibetan Plateau.
\end{abstract}

\section{Introduction}

Precipitation is one of the essential meteorological inputs of a hydrologic model and the key driving force for a hydrologic cycle. Errors in precipitation estimation can bring significant uncertainties in streamflow simulation and prediction (Sorooshian et al., 2011). Three methods are generally used to measure precipitation: traditional gauge observations, meteorological radar observations, and satellite observations (Ashouri et al., 2015). In many remote regions and mountainous areas, rain gauges and meteorological radar networks are either sparse or non-existent. Thus, satellite-based precipitation is of great importance in such regions. For instance, there is a great potential for using satellite-based precipitation estimates on the Tibetan Plateau known as the "roof of the world" with an average elevation of over $4000 \mathrm{~m}$ (Yao et al., 2012). Owing to a harsh environment, the existing meteorological stations managed by the Chinese Meteorological Administration only form an extremely sparse network, which creates great challenges for water resources management and operation. For example, on average, there is only 0.3 and 1 station per grid of $1^{\circ} \times 1^{\circ}$ in the upper Yangtze and upper Yellow river basins, respectively (Xue et al., 2013a). Moreover, the spatial distribution of the meteorological stations is highly uneven and most stations are located around the river channel with relatively low elevation (Fig. 1). Therefore, streamflow simulation using the limited gauge-based rainfall information might not be reliable due to the input uncertainties with such a poor spatial resolution. Satellite-based rainfall products have the advantage of good 


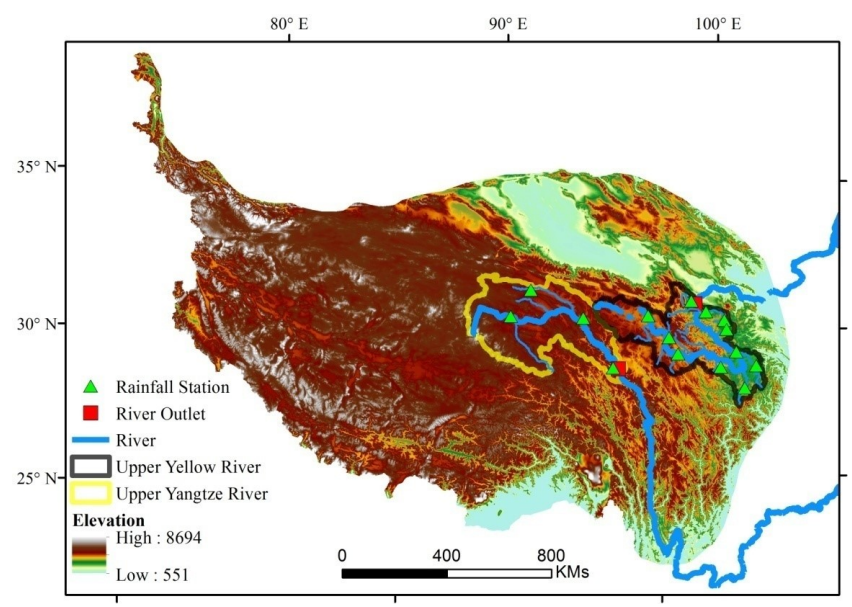

Figure 1. The selected river basins (the upper Yellow River and Yangtze River basin) on the Tibetan Plateau and location of rainfall stations and river outlets.

spatial coverage, which could allow for an accurate streamflow simulation on the Tibetan Plateau. Besides precipitation estimation from satellites, the Global Land Data Assimilation System (GLDAS), as a global-scale terrestrial modeling system, is also capable of providing good spatial coverage to solve the issue of insufficient observation data over the Tibetan Plateau area (Wang et al., 2011).

According to Kidd and Levizzani (2011), during the last decade satellite-based precipitation estimates have reached a good level of maturity. Currently, many satellite rainfall products are available and have been extensively used globally (e.g., Sorooshian et al., 2000; Huffman et al., 2001; Adler et al., 2003; Xie et al., 2003; Joyce et al., 2004; Turk and Miller, 2005; Miao et al., 2010, 2011). Recently, a new satellite-based precipitation product was released by the National Climatic Data Center (NCDC), which is termed Precipitation Estimation from Remotely Sensed Information Using Artificial Neural Networks - Climate Data Record (PERSIANN-CDR) (Ashouri et al., 2015). PERSIANNCDR is a multi-satellite, high-resolution and post-time rainfall product that provides daily precipitation estimates at $0.25^{\circ}$ spatial resolution from 1 January 1983 to the present. According to Ashouri et al. (2015), the PERSIANN-CDR rainfall product uses the archive of gridded satellite (GridSatB1) infrared radiation (IR) data (Knapp, 2008) as the input to the artificial neural network algorithm. The retrieval algorithm uses IR satellite data from global geosynchronous satellites as the primary source of precipitation information. To meet the calibration requirement of PERSIANN, the model is pre-trained using the National Centers for Environmental Prediction stage IV hourly precipitation data. Then, the parameters of the model are kept fixed and the model is run for the full historical record of GridSat-B1 IR data. To reduce the biases in the estimated precipitation, while preserving the temporal and spatial patterns in high resolution, the resulting estimates are then adjusted using the Global Precipitation Climatology Project (GPCP) monthly $2.5^{\circ}$ precipitation products. The performance of the PERSIANN-CDR rainfall product has been tested and reported in different regions (e.g., Ashouri et al., 2015; Miao et al., 2015; Zhu et al., 2016). Ashouri et al. (2015) found that PERSIANN-CDR precipitation is performing reasonably well when compared with radar and ground-based observations in the 1986 Sydney flood event of Australia and the 2005 Hurricane Katrina of the United States. Zhu et al. (2016) compared precipitation estimation from PERSIANN-CDR, Tropical Rainfall Measuring Mission 3B42 Version 7 (TRMM-3B42-V7), and Climate Prediction Center morphing technique (CMORPH) over the Xiang and Qu River basins in China and demonstrated the accuracy of PERSIANN-CDR. Miao et al. (2015) showed that PERSIANN-CDR rainfall product is able to capture the spatial and temporal characteristics of extreme precipitation events at daily scale in the eastern China monsoon region when compared with a ground-based precipitation dataset. Miao et al. (2015) also pointed out that the correlation between the PERSIANN-CDR precipitation and ground-based precipitation is not strong on the Tibetan Plateau and speculated that the sparse ground-based gauge stations may result in uncertainties with the use of ground-based precipitation estimates as a reference on the Tibetan Plateau. Building on Miao et al. (2015), in this study, PERSIANN-CDR is further applied to a conceptual hydrological model to simulate streamflow of two river basins on the Tibetan Plateau, and is compared with the limited gauge information, and the precipitation from GLDAS with regard to their streamflow simulation capabilities.

Many studies have been carried out to evaluate the suitability of a number of satellite-based precipitation estimate products in forcing hydrologic models and simulating streamflow for various regions around the world (e.g., Yilmaz et al., 2005; Artan et al., 2007; Su et al., 2011; Bitew et al., 2012; Yong et al., 2012, Yang et al., 2015). However, there are few evaluation studies focusing on hydrological modeling driven by satellite rainfall products on the Tibetan Plateau. Among a limited number of studies, Tong et al. (2014) evaluated the streamflow simulation capability of four satellite products (TRMM-3B42-V7, TRMM-3B42RT-V7, PERSIANN, and $\mathrm{CMORPH}$ ) using the variable infiltration capacity (VIC) hydrologic model in two sub-basins over the Tibetan Plateau and concluded that the TRMM-3B42-V7 and CMORPH datasets have relatively better performance than the others. One of the limitations is that the data length of many satellite precipitation products, such as TRMM-3B42RT-V7 and CMORPH, start from 2000 to the present, which is rather short. In this study, there is no such limitation because the PERSIANN-CDR daily rainfall product includes more than 33 years of data and the length of data grows every year. In Tong et al. (2014), the rain gauge is set to be the reference to compare different satellite-based rainfall products. However, given the fact that (1) density of rain gauges on the 
Tibetan Plateau is rather low as compared to other regions in China, (2) distribution of gauges are uneven according to Miao et al. (2015), and (3) rain gauges are located in lowelevation river channels (Fig. 1), the authors have the similar concern as Miao et al. (2015) that the use of a sparse rain gauge as reference to compare satellite products is questionable. Therefore, in this study, precipitation from a limited gauge network, GLDAS precipitation, and PERSIANN-CDR precipitation are used as the inputs of a hydrologic model for streamflow simulation on two major river basins, the upper Yangtze River basin and the upper Yellow River basin, on the Tibetan Plateau. Then, the simulation results are compared with observed streamflow, which is believed to be a more reliable reference than the limited rainfall observation to judge the qualities of satellite rainfall products on the Tibetan Plateau. Potential sources of uncertainties are also discussed with regard to the parameterization of the hydrological model and the length of data used for calibration.

\section{Study region, data, and hydrological modeling}

\subsection{Study region and data}

Two river basins on the northern Tibetan Plateau, namely, the upper Yangtze River (UYZR) and upper Yellow River (UYLR) basins are selected, which have a long daily streamflow record from 1983 to 2012. As shown with red squares in Fig. 1, two hydrological stations, Tangnaihai and Zhimenda, are the outlet stations of the UYZR and UYLR, which have total drainage areas of 121972 and $137704 \mathrm{~km}^{2}$, respectively. Elevation in the region varies from 3450 to $6621 \mathrm{~m}$. According to Yao et al. (2012), the climate system of the two regions has distinct summer Indian monsoon and East Asian monsoon characteristics during summer. Figure 1 shows the distribution of meteorological and hydrological stations in the two basins. The green triangles show the location of rain gauges, which are rather unevenly distributed and sparse as compared to the gauge distribution of China available from Miao et al. (2015).

The observed daily streamflow data from 1983 to 2012 at the outlets of the two basins are provided by the Ministry of Water Resources of China. The runoff is calculated by dividing streamflow by corresponding basin area. The daily gauge meteorological data in the two basins from 1983 to 2012 are obtained from the China Meteorological Administration (http://data.cma.cn/en). There are 4 and 11 meteorological stations in the UYZR and UYLR, respectively, which means that on average there is only 0.3 and 1 station per grid of $1^{\circ} \times 1^{\circ}$ in the two basins, respectively. The precipitation data in GLDAS come from three different sources: the Climate Prediction Center Merged Analysis of Precipitation, Global Data Assimilation System, and the European Centre for Medium-Range Weather Forecasts (Rodell et al., 2004). The precipitation data used in GLDAS are a combi- nation of reanalysis and observations, which is believed to have the advantages of different data sources (Gottschalck et al., 2005). In this study, the $1.0^{\circ}$ resolution GLDAS precipitation dataset is re-sampled into $0.25^{\circ} \times 0.25^{\circ}$ grids and used as the input of streamflow simulations (http://ldas.gsfc.nasa. gov/gldas/). The PERSIANN-CDR rainfall dataset is available at the NOAA NCDC website (ftp://data.ncdc.noaa.gov/ cdr/persiann/files/), as well as the Center for Hydrometeorology and Remote Sensing at the University of California, Irvine. In order to compare the PERSIANN-CDR with gauge observations, the gauge precipitation is interpolated into $0.25^{\circ} \times 0.25^{\circ}$ grids with the inverse distance-weighting interpolation method, which has been demonstrated as being efficient in precipitation interpolation applications (e.g., Nalder and Wein, 1998; Garcia et al., 2008; Ly et al., 2011). The daily gauge-based precipitation, GLDAS precipitation, and PERSIANN-CDR precipitation for basin average are compared by the cumulative distribution functions (CDFs) of daily precipitation values (e.g., Sheffield et al., 2014; Zhang and Tang, 2015), whereby the two-parameter Gamma distribution function (Thom, 1958) is used to fit the data.

\subsection{Hydrological modeling}

The hydrologic model used in this study is the Hydroinformatic Modeling System (HIMS) rainfall-runoff model (Liu et al., 2006, 2008, 2010a, b), which is one of the operational hydrological models by the Tibet Government in China. The HIMS model is a grid-based hydrologic model, which is able to simulate the dominant hydrological processes such as actual evapotranspiration, infiltration, runoff, groundwater recharge, and channel routing. In the HIMS model, a catchment is divided into grids, and grids are linked throughout the stream network based on topological relationships of channel network and properties of soil, vegetation, and land use. In each grid, actual evaporation is calculated by a formulation between soil water content and potential evapotranspiration. Potential evapotranspiration $\mathrm{ET}_{0}$ (Hargreaves and Samani, 1985) and actual evaporation $\mathrm{ET}_{\mathrm{a}}$ are described as follows:

$$
\begin{aligned}
& \mathrm{ET}_{0}=0.00023 \cdot \mathrm{RA} \cdot(T+17.8) \cdot\left(T_{\text {max }}-T_{\min }\right)^{0.50}, \\
& \mathrm{ET}_{\mathrm{a}}(t)=\mathrm{ET}_{0}(t) \cdot\left(1-\left(1-\frac{\mathrm{SMS}_{t}}{\mathrm{SMSC}}\right)^{C}\right),
\end{aligned}
$$

where RA is extraterrestrial radiation $\left(\mathrm{MJ} \mathrm{m}^{-2} \mathrm{day}^{-1}\right) ; T$, $T_{\max }$, and $T_{\min }$ are daily average, maximum, and minimum temperatures $\left({ }^{\circ} \mathrm{C}\right)$, respectively; $L$ is latent heat of vaporization $\left(\mathrm{MJ} \mathrm{kg}^{-1}\right)$; SMS and SMSC are soil moisture storage and the maximum soil storage capacity $(\mathrm{mm})$, respectively; and $C$ is the evapotranspiration coefficient to be calibrated.

The infiltration process is modeled using an empirical relationship, which has been confirmed through analysis of data measured in a number of experimental watersheds and various physical geographic factors in China (Liu et al., 2006):

$f_{t}=R \cdot P_{t}^{r}$, 
where $f_{t}$ is infiltration $(\mathrm{mm})$ and $P_{t}$ is precipitation $(\mathrm{mm})$, and $R$ and $r$ are parameters. Surface runoff $\left(\mathrm{RS}_{t} ; \mathrm{mm}\right)$ is calculated by

$\mathrm{RS}_{t}=P_{t}-f_{t}=P_{t}-R \cdot P_{t}^{r}$.

According to the saturation excess mechanism and spatial variability of watershed characteristics, interflow and groundwater recharge are estimated as linear functions of soil wetness (soil moisture amount divided by soil moisture capacity). Baseflow is simulated based on the linear reservoir assumption, in which the relationship between groundwater storage and outflow is linear. Interflow (RI; $\mathrm{mm}$ ), groundwater recharge (REC; $\mathrm{mm}$ ), baseflow (RG; $\mathrm{mm}$ ), and total runoff (TR; $\mathrm{mm}$ ) are determined by

$\mathrm{RI}_{t}=L_{\mathrm{a}} \times\left(\frac{\mathrm{SMS}_{t}}{\mathrm{SMSC}}\right) \times f_{t}$,

$\mathrm{REC}_{t}=R_{\mathrm{c}} \times\left(\frac{\mathrm{SMS}_{t}}{\mathrm{SMSC}}\right) \times\left(f_{t}-\mathrm{RI}_{t}\right)$,

$\mathrm{RG}_{t}=K_{\mathrm{b}} \times\left(\mathrm{GW}_{t}+\mathrm{REC}_{t}\right)$,

$\mathrm{TR}_{t}=\mathrm{RS}_{t}+\mathrm{RI}_{t}+\mathrm{RG}_{t}$,

where $L_{\mathrm{a}}, R_{\mathrm{c}}$, and $K_{\mathrm{b}}$ are coefficients for interflow, groundwater recharge, and baseflow, respectively; SMSC is the maximum value of soil moisture storage capacity $(\mathrm{mm})$; SMS is the actual soil moisture storage $(\mathrm{mm})$; and $\mathrm{GW}$ is groundwater storage $(\mathrm{mm}) . L_{\mathrm{a}}, R_{\mathrm{c}}, K_{\mathrm{b}}$, and SMSC are the parameters in need of calibration. The degree-day snowmelt algorithm (Hock, 2003), assuming an empirical relationship between air temperature and snowmelt rate, is used to simulate snowmelt runoff. The air temperature within each grid is adjusted by a commonly used temperature lapse rate $\left(0.65^{\circ} \mathrm{C} / 100 \mathrm{~m}\right)$. The degree-day factor of snowmelt is set to $4.1 \mathrm{~mm}^{\circ} \mathrm{C}^{-1}$ day $^{-1}$ in the two basins based on the investigation of Zhang et al. (2006). Surface runoff and baseflow for each grid are routed to the basin outlet through a channel network. The Muskingum method (Franchini and Lamberti, 1994) is used for flow channel routing. The detail descriptions and the conceptual diagram showing the configuration of HIMS model are available in Liu et al. (2008) and Jiang et al. (2015).

The HIMS model is set up at $0.25^{\circ} \times 0.25^{\circ}$ spatial resolution grids in the two river basins. There are nine parameters requiring calibration in the HIMS model (Table 1). The Shuffle Complex Evolution method (SCE-UA) is used for calibrating the model parameters (Duan et al., 1992). The optimization objective is to maximize the Nash-Sutcliffe efficiency (NSE) (Nash and Sutcliffe, 1970) between the simulated and measured daily streamflow. There are two stopping criteria for calibrating the parameters. The first one is the evolution of all simplexes have converged to a limited parameter space, which is the default convergence criterion of SCE-UA. Another stopping criterion is the maximum number of function evaluation set by users is met. In our study, the settings for SCE-UA are the maximum numbers of function evaluation equal to $5 \times 10^{8}$, numbers of complexes equal to 2 , which give a total population of 38 , and the percentage change allowed to define convergence is set to $1 \times 10^{-6}$. The calibration period is from 1983 to 1997 and the verification period is from 1998 to 2012. The performance of the streamflow simulation is evaluated by comparing simulated and observed streamflow through two statistics: NSE and relative bias $(\mathrm{Rb})$ between simulated and observed streamflow:

$$
\begin{aligned}
& \mathrm{NSE}=1-\frac{\sum_{i=1}^{N}\left(Q_{\mathrm{obs}, i}-Q_{\mathrm{sim}, i}\right)^{2}}{\sum_{i=1}^{N}\left(Q_{\mathrm{obs}, i}-\overline{Q_{\mathrm{obs}}}\right)^{2}}, \\
& \mathrm{Rb}=\frac{\sum_{i=1}^{N}\left(Q_{\mathrm{sim}, i}-Q_{\mathrm{obs}, i}\right)}{\sum_{i=1}^{N} Q_{\mathrm{obs}, i}},
\end{aligned}
$$

where $Q_{\text {sim }}$ and $Q_{\text {obs }}$ are the simulated and observed streamflow, respectively; $\overline{Q_{\mathrm{obs}}}$ is the mean of the observed streamflow; and $N$ is the total number of days in the calibration period.

\section{Results}

\subsection{Hydrometeorological characteristics of the two basins}

Figure 2 and Table 2 show the average monthly amounts of precipitation and runoff in the UYZR and UYLR from 1983 to 2012. These two river basins have distinct dry and wet seasons, which are from September to February, and March to October, respectively. According to Table 2, precipitation between May and October (wet season) accounts for 92.5 and $90.1 \%$ of the annual total precipitation for the UYZR and UYLR, respectively. Similar to the temporal distribution of precipitation, runoff during May to October accounts for 87.6 and $78.4 \%$ of annual runoff in the UYZR and UYLR, respectively. Given the seasonal concurrence of precipitation and runoff, precipitation in the wet season plays a dominant role in annual runoff generation in these two river basins. The runoff coefficients are $0.22,0.27$, and 0.26 in the UYZR based on gauge-based precipitation, GLDAS precipitation, and PERSIANN-CDR precipitation, respectively. In the UYLR, the runoff coefficients are 0.29, 0.31, and 0.29 based on the three precipitation datasets, respectively. 
Table 1. Description of HIMS model parameters and allowable ranges.

\begin{tabular}{llr}
\hline Parameter & Description & Allowable range \\
\hline SMSC & The maximum soil storage capacity $(\mathrm{mm})$ & $50-1000$ \\
$R$ & The infiltration coefficient & $0.1-2$ \\
$r$ & The infiltration coefficient & $0.1-1$ \\
$L_{\mathrm{a}}$ & The interflow coefficient & $0.1-2$ \\
$R_{\mathrm{C}}$ & The groundwater recharge coefficient & $0.01-2$ \\
$C$ & The evapotranspiration coefficient & $0.001-10$ \\
$K_{\mathrm{b}}$ & The baseflow coefficient & $0.001-1$ \\
$C_{1}$ & The Muskingum coefficient & $0.001-1$ \\
$C_{2}$ & The Muskingum coefficient & $0.001-1$ \\
\hline
\end{tabular}

Table 2. Average monthly precipitation and runoff in the upper Yangtze and Yellow River basins.

\begin{tabular}{lrrrr|rrrr}
\hline & \multicolumn{3}{c|}{ Upper Yangtze River } & \multicolumn{3}{c}{ Upper Yellow River } \\
\cline { 2 - 9 } Period & $\begin{array}{r}\text { Rain_ } \\
\text { Gauge }\end{array}$ & $\begin{array}{r}\text { Rain_- } \\
\text { GLDAS }\end{array}$ & $\begin{array}{r}\text { Rain_} \\
\text { CDR }\end{array}$ & $\begin{array}{r}\text { Runoff_ } \\
\text { OBS }\end{array}$ & $\begin{array}{r}\text { Rain_ } \\
\text { Gauge }\end{array}$ & $\begin{array}{r}\text { Rain_ } \\
\text { GLDAS }\end{array}$ & $\begin{array}{r}\text { Rain_ } \\
\text { CDR }\end{array}$ & $\begin{array}{r}\text { Runoff_- } \\
\text { OBS }\end{array}$ \\
\hline Jan & 3.3 & 4.0 & 1.4 & 1.3 & 4.4 & 5.3 & 3.2 & 3.7 \\
Feb & 3.4 & 4.8 & 2.5 & 1.2 & 6.5 & 7.5 & 5.2 & 3.7 \\
Mar & 5.0 & 8.1 & 7.5 & 1.5 & 12.9 & 16.2 & 13.1 & 4.8 \\
Apr & 10.2 & 16.2 & 14.6 & 3.0 & 23.7 & 28.0 & 25.0 & 7.7 \\
May & 37.9 & 34.6 & 38.2 & 5.6 & 62.9 & 62.3 & 65.3 & 11.9 \\
Jun & 90.4 & 66.3 & 72.0 & 12.9 & 107.6 & 96.2 & 104.6 & 20.4 \\
Jul & 105.8 & 87.6 & 87.8 & 21.6 & 113.5 & 110.3 & 111.8 & 29.6 \\
Aug & 88.6 & 69.0 & 74.5 & 20.6 & 92.0 & 93.3 & 94.0 & 23.3 \\
Sep & 66.9 & 49.8 & 53.2 & 16.0 & 83.4 & 83.7 & 84.4 & 22.2 \\
Oct & 20.2 & 18.0 & 20.5 & 9.1 & 35.3 & 36.0 & 41.4 & 19.4 \\
Nov & 2.5 & 3.9 & 1.7 & 3.5 & 5.0 & 5.8 & 7.3 & 10.0 \\
Dec & 2.3 & 2.0 & 0.5 & 1.6 & 3.0 & 3.3 & 1.5 & 5.0 \\
\hline May to Oct & 409.7 & 325.3 & 346.1 & 85.8 & 494.6 & 481.8 & 501.4 & 126.8 \\
Annual & 436.4 & 364.3 & 374.3 & 98.0 & 550.2 & 547.9 & 556.6 & 161.8 \\
Ratio & 93.9 & 89.3 & 92.5 & 87.6 & 89.9 & 87.9 & 90.1 & 78.4 \\
\hline
\end{tabular}

Note: Rain_gauge, Rain_GLDAS and Rain_CDR indicate gauge-based precipitation GLDAS precipitation and

PERSIANN-CDR precipitation ( $\mathrm{mm})$, respectively. Runoff_OBS indicates observed runoff $(\mathrm{mm})$. Ratio means the percentage of precipitation and streamflow during May to November to annual values.

\subsection{Comparison between gauge-based precipitation, GLDAS precipitation, and PERSIANN-CDR precipitation}

Figure 3 shows the spatial distribution of average annual values of $1.0^{\circ}$ resolution GLDAS precipitation and $0.25^{\circ}$ resolution PERSIANN-CDR precipitation. The spatial patterns of the two dataset are generally consistent with each other. Figure 4 shows the comparison of CDFs for basinaveraged daily gauge-based precipitation, GLDAS precipitation, and PERSIANN-CDR precipitation in the UYZR and UYLR from 1983 to 2012. At a given probability, GLDAS precipitation generally has the smallest values, followed by PERSIANN-CDR precipitation and gauge-based precipitation in the UYZR. In the UYLR, the CDFs of PERSIANNCDR precipitation, GLDAS precipitation, and gauge-based precipitation show overall better agreement than that in the UYZR. Table 2 shows the average amounts of gaugebased precipitation, GLDAS precipitation, and PERSIANNCDR precipitation. In the UYZR, the average annual precipitation is $436.4 \mathrm{~mm}$ from gauge-based data, $365.1 \mathrm{~mm}$ from GLDAS dataset, and $374.3 \mathrm{~mm}$ from PERSIANNCDR product. Gauge-based annual precipitation is $16.6 \%$ larger than PERSIANN-CDR annual precipitation. In the UYLR, average annual amounts of gauge-based precipitation, GLDAS precipitation, and PERSIANN-CDR precipitation are similar, which are 550.2, 547.9, and $556.6 \mathrm{~mm}$, respectively (Table 2).

\subsection{Streamflow simulation in the two basins}

Due to the previously mentioned concern that a sparse gauge network and its interpolation cannot perfectly describe the spatial and temporal rainfall characteristics at river basin 

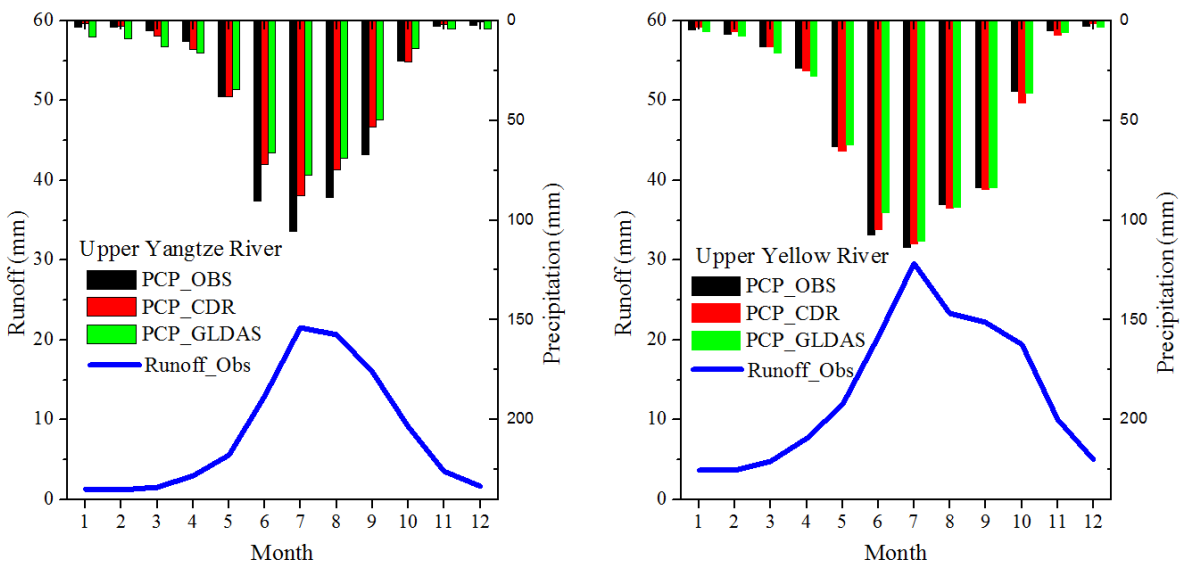

Figure 2. The monthly average runoff observed at the river outlet of the upper Yangtze River and Yellow River basin, and the precipitation data retrieved from ground-based observation, GLDAS, and PERSIANN-CDR product.

Table 3. Calibrated parameter values in the HIMS model for the upper Yangtze and Yellow River basins.

\begin{tabular}{llrrrrrrrrr}
\hline Basin & Input & SMSC & $R$ & $r$ & $L_{\mathrm{a}}$ & $R_{\mathrm{c}}$ & $C$ & $K_{\mathrm{b}}$ & $C_{1}$ & $C_{2}$ \\
\hline Yangtze & Gauge_based & 302.5 & 1.47 & 0.78 & 0.74 & 0.05 & 0.67 & 0.15 & 0.18 & 0.81 \\
& GLDAS & 339.2 & 1.72 & 0.87 & 0.82 & 0.07 & 0.58 & 0.18 & 0.17 & 0.81 \\
& PERSIANN-CDR & 343.8 & 1.71 & 0.89 & 0.87 & 0.07 & 0.56 & 0.18 & 0.17 & 0.82 \\
Yellow & Gauge_based & 334.8 & 2.08 & 0.77 & 1.00 & 0.03 & 0.44 & 0.14 & 0.14 & 0.86 \\
& GLDAS & 332.5 & 2.10 & 0.76 & 1.02 & 0.03 & 0.39 & 0.14 & 0.15 & 0.85 \\
& PERSIANN-CDR & 342.1 & 2.01 & 0.73 & 0.98 & 0.05 & 0.45 & 0.14 & 0.12 & 0.88 \\
\hline
\end{tabular}
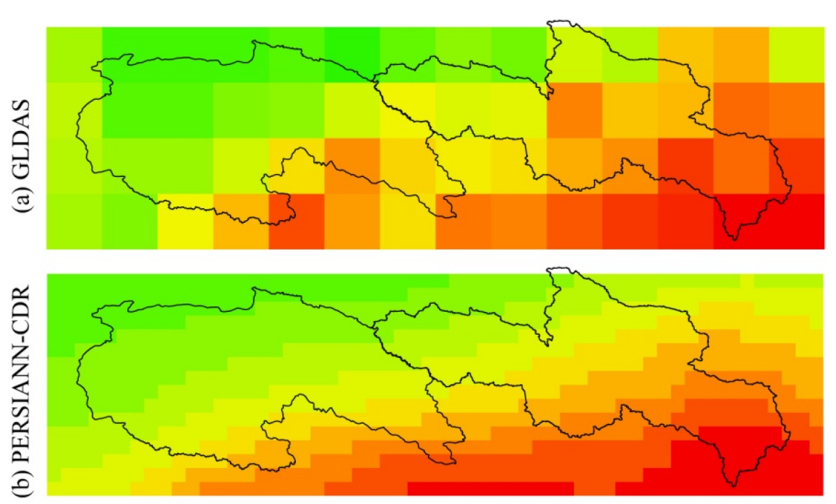

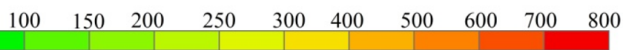

Figure 3. The spatial distribution of average annual values of $1.0^{\circ}$ resolution GLDAS precipitation (a) and $0.25^{\circ}$ resolution PERSIANN-CDR precipitation (b).

scale, the alternative is to evaluate the streamflow simulated instead of treating the sparse gauge network as reference. In this section, the streamflow simulated by gauge-based precipitation, GLDAS precipitation, and PERSIANN-CDR precipitation is derived from HIMS, and compared with observed streamflows at the outlet in the UYZR and UYLR. The HIMS model is separately calibrated by maximizing the
NSE between observed streamflow and simulated streamflow driven by gauge-based precipitation, GLDAS precipitation, and PERSIANN-CDR precipitation from 1983 to 1997. Table 3 shows the calibrated parameter values of the HIMS model for the two basins. Figure 5 shows daily observed streamflow and simulated streamflow driven by gauge-based precipitation, GLDAS precipitation, and PERSIANN-CDR precipitation for the two basins from 1983 to 2012. In the UYZR (Fig. 5a, b and c), the NSE values are 0.63, 0.78, and 0.77 in the calibration period driven by gauge-based precipitation, GLDAS precipitation, and PERSIANN-CDR precipitation, respectively, whereas they are $0.60,0.71$, and 0.73 in the verification period. In both the calibration and verification period, the NSE values from GLDAS precipitation and PERSIANN-CDR precipitation are greater than that from gauge-based precipitation, which indicates that using GLDAS precipitation and PERSIANN-CDR precipitation as input to the HIMS model is able to generate more accurate streamflow than using gauge-based precipitation in the UYZR. In the UYLR (Fig. 5d, e and f), the NSE values between daily observed streamflow and simulated streamflow are $0.82,0.78$, and 0.80 in the calibration period driven by gauge-based precipitation, GLDAS precipitation, and PERSIANN-CDR precipitation, respectively. In the verification period, the NSE values are $0.81,0.77$, and 0.78 for the three types of data. The high NSE values in both 

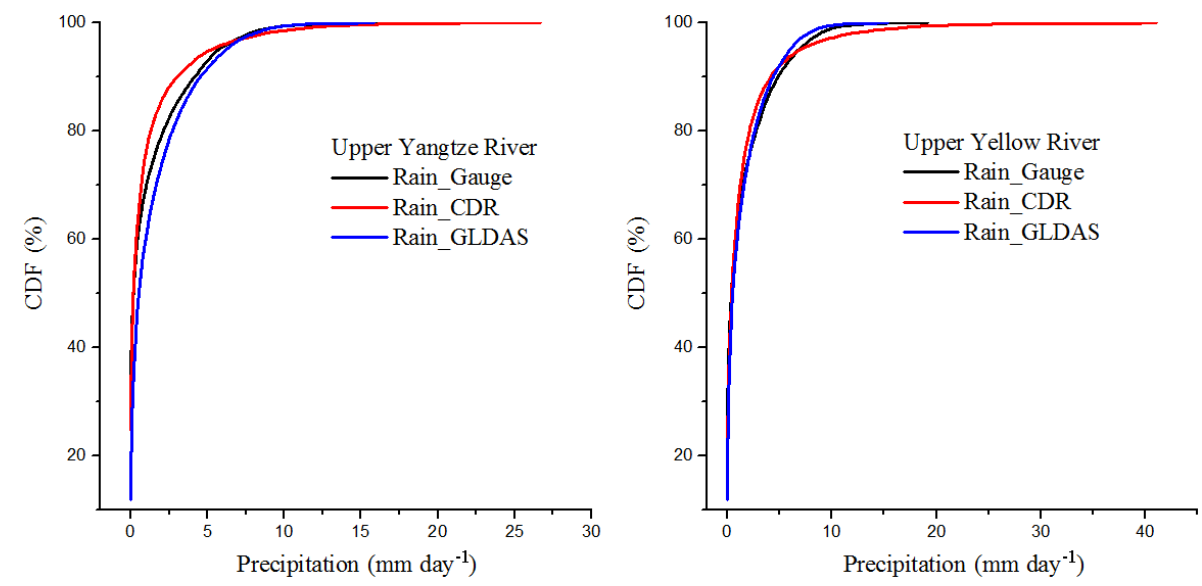

Figure 4. The calculated CDF of daily gauge-based precipitation, GLDAS precipitation, and PERSIANN-CDR precipitation in the upper Yangtze River basin and upper Yellow River basin.

Table 4. The performances of streamflow simulations driven by gauge-based precipitation, GLDAS precipitation, and PERSIANN-CDR precipitation in the two basins.

\begin{tabular}{|c|c|c|c|c|c|c|c|c|c|c|c|c|c|c|}
\hline \multirow[b]{2}{*}{ Period } & \multicolumn{7}{|c|}{ Upper Yangtze River } & \multicolumn{7}{|c|}{ Upper Yellow River } \\
\hline & $\begin{array}{l}\mathrm{Q}_{-} \\
\text {obs }\end{array}$ & $\begin{array}{c}\mathrm{Qs}_{-} \\
\text {gauge }\end{array}$ & $\begin{array}{c}\mathrm{Qs}_{-} \\
\text {GLDAS }\end{array}$ & $\begin{array}{l}\mathrm{Qs}_{-} \\
\mathrm{CDR}\end{array}$ & $\begin{array}{c}\mathrm{Rb}_{-} \\
\text {gauge }\end{array}$ & $\begin{array}{c}\mathrm{Rb}_{-} \\
\text {GLDAS }\end{array}$ & $\begin{array}{l}\mathrm{Rb}_{-} \\
\mathrm{CDR}\end{array}$ & $\begin{array}{l}\text { Q- } \\
\text { obs }\end{array}$ & $\begin{array}{c}\mathrm{Qs}_{-} \\
\text {gauge }\end{array}$ & $\begin{array}{c}\mathrm{Qs}_{-} \\
\text {GLDAS }\end{array}$ & $\begin{array}{c}\mathrm{Qs}_{-} \\
\mathrm{CDR}\end{array}$ & $\begin{array}{c}\mathrm{Rb}_{-} \\
\text {gauge }\end{array}$ & $\begin{array}{c}\mathrm{Rb}_{-} \\
\text {GLDAS }\end{array}$ & $\begin{array}{c}\mathrm{Rb}_{-} \\
\mathrm{CDR}\end{array}$ \\
\hline Jan & 68.1 & 48.4 & 40.4 & 32.8 & -28.9 & -40.7 & -51.8 & 168.9 & 65.7 & 71.4 & 68.0 & -61.1 & -57.7 & -59.8 \\
\hline Feb & 68.3 & 32.7 & 30.2 & 24.9 & -52.1 & -55.8 & -63.5 & 168.3 & 61.6 & 67.6 & 60.5 & -63.4 & -59.8 & -64.1 \\
\hline Mar & 76.9 & 70.2 & 75.3 & 72.4 & -8.7 & -2.1 & -5.8 & 219.7 & 110.5 & 145.1 & 138.0 & -49.7 & -34.0 & -37.2 \\
\hline Apr & 158.6 & 153.2 & 158.3 & 147.5 & -3.4 & -0.2 & -7.0 & 352.0 & 299.0 & 311.5 & 302.5 & -15.1 & -11.5 & -14.0 \\
\hline May & 289.2 & 253.5 & 262.1 & 273.4 & -12.3 & -9.4 & -5.5 & 543.6 & 512.9 & 514.9 & 524.9 & -5.7 & -5.3 & -3.4 \\
\hline Jun & 683.9 & 750.5 & 679.1 & 698.4 & 9.7 & -0.7 & 2.1 & 928.5 & 968.6 & 921.3 & 946.6 & 4.3 & -0.8 & 1.9 \\
\hline Jul & 1108.9 & 1306.9 & 1102.5 & 1111.4 & 17.9 & -0.6 & 0.2 & 1350.1 & 1386.6 & 1420.2 & 1431.3 & 2.7 & 5.2 & 6.0 \\
\hline Aug & 1059.7 & 1204.0 & 1042.8 & 1063.2 & 13.6 & -1.6 & 0.3 & 1061.1 & 1141.4 & 1102.7 & 1088.5 & 7.6 & 3.9 & 2.6 \\
\hline Sep & 850.7 & 977.4 & 897.2 & 918.9 & 14.9 & 5.5 & 8.0 & 1009.6 & 1059.7 & 1062.6 & 1075.7 & 5.0 & 5.2 & 6.5 \\
\hline Oct & 469.4 & 428.1 & 407.2 & 420.1 & -8.8 & -13.3 & -10.5 & 883.7 & 859.1 & 861.3 & 876.5 & -2.8 & -2.5 & -0.8 \\
\hline Nov & 187.6 & 169.0 & 182.3 & 161.1 & -9.9 & -2.8 & -14.1 & 457.3 & 429.1 & 437.8 & 456.6 & -6.2 & -4.3 & -0.2 \\
\hline Dec & 84.5 & 28.2 & 27.5 & 24.5 & -66.7 & -67.5 & -71.0 & 227.0 & 100.7 & 132.8 & 127.5 & -55.7 & -41.5 & -43.9 \\
\hline May-Oct & 743.4 & 819.6 & 731.9 & 746.9 & 10.3 & -1.5 & 0.5 & 962.7 & 987.7 & 980.5 & 990.4 & 2.6 & 1.8 & 2.9 \\
\hline Nov-Apr & 107.2 & 83.6 & 85.6 & 77.2 & -22.1 & -20.1 & -28.0 & 265.6 & 177.6 & 194.2 & 192.3 & -33.1 & -26.9 & -27.6 \\
\hline Annual & 427.9 & 454.6 & 408.7 & 414.8 & 6.2 & -4.5 & -3.1 & 617.0 & 586.0 & 587.8 & 594.6 & -5.0 & -4.7 & -3.6 \\
\hline
\end{tabular}

Note: Q_obs indicates observed runoff $\left(\mathrm{m}^{3} \mathrm{~s}^{-1}\right)$. Qs_gauge, Qs_GLDAS, and Qs_CDR indicate streamflow simulations ( $\mathrm{m}^{3} \mathrm{~s}^{-1}$ ) driven by the gauge-based precipitation, GLDAS precipitation, and PERSIANN-CDR precipitation, respectively. Rb_gauge, Rb_GLDAS, and Rb_CDR indicate relative bias between observed streamflow and simulated streamflow driven by the gauge-based precipitation, GLDAS precipitation, and PERSIANN-CDR precipitation, respectively.

the calibration and verification periods suggest that gaugebased precipitation, GLDAS precipitation, and PERSIANNCDR precipitation have similar performances as the drivers of streamflow simulation in the UYLR.

Figure 6 and Table 4 compare the simulated and observed average monthly streamflow for the two basins. In the UYZR, the relative bias between observed streamflow and simulated streamflow driven by gauge-based precipitation is $10.3 \%$ in the wet season, which suggests a considerable overestimate of streamflow. Comparably, the relative bias between observed streamflow and simulated streamflow driven by GLDAS precipitation and PERSIANN-CDR precipitation is -1.5 and $0.5 \%$ the in wet season, respectively. As compared with the wet season streamflow simulation re- sults with gauge-based precipitation, the simulated streamflows driven by GLDAS precipitation and PERSIANN-CDR precipitation are closer to the observed streamflow. In the dry season, streamflow simulations driven by gauge-based precipitation, GLDAS precipitation, and PERSIANN-CDR precipitation all underestimate streamflow with relative bias of $-22.1,-20.1$, and $-28.0 \%$ in the UYZR, respectively. In the UYLR, all the three precipitation products slightly overestimate the streamflow in the wet season with relative bias of $2.6,1.8$, and $2.9 \%$. Similar to the results in the UYZR, streamflow simulations driven by gauge-based precipitation, GLDAS precipitation, and PERSIANN-CDR precipitation have similar good performances in the wet season in the UYLR. However, all the three precipitation products 

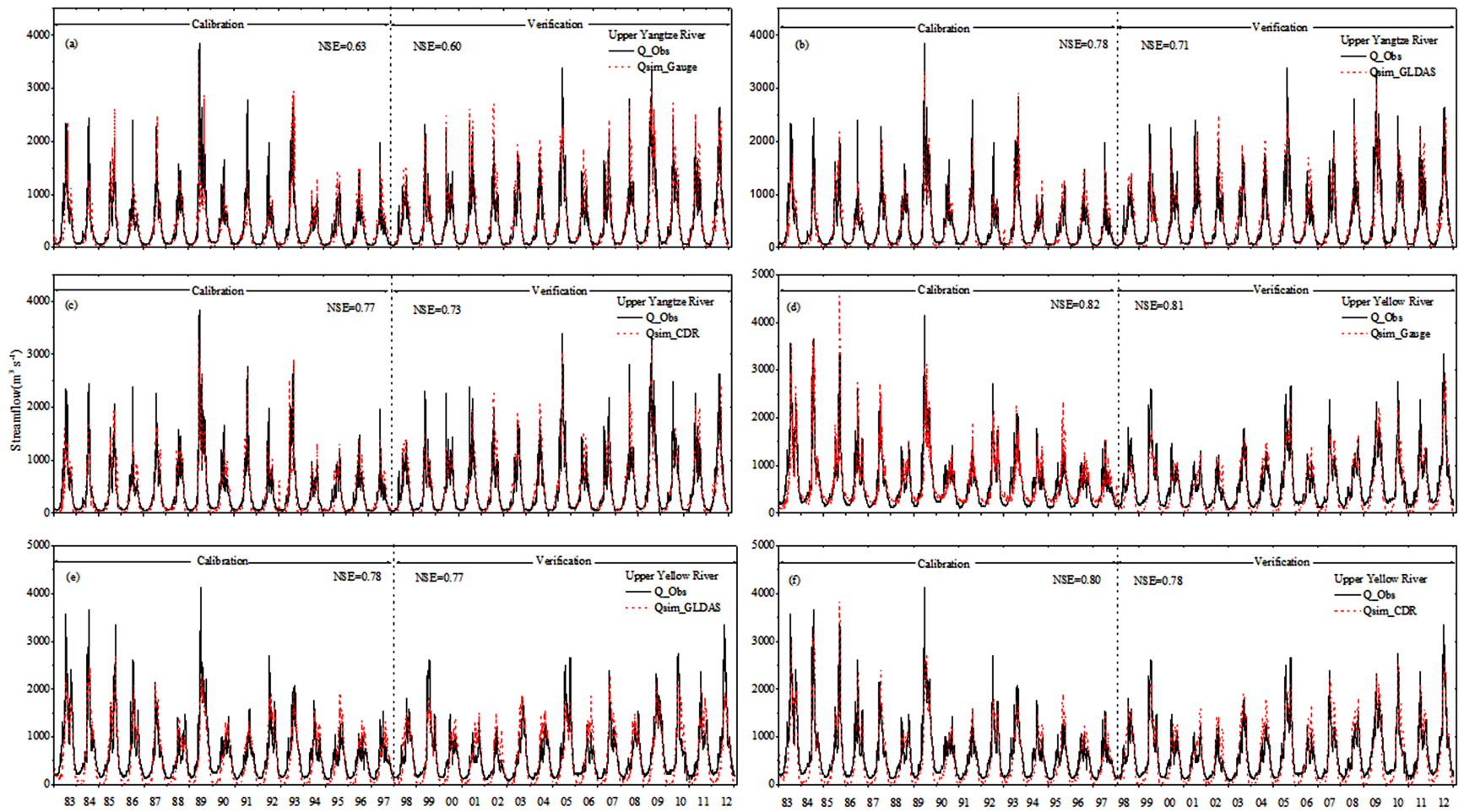

Figure 5. The comparison between the simulated daily streamflow (red) with ground-based, GLDAS, and PERSIANN-CDR precipitation and the observed data (black) at the outlets of the upper Yangtze River basin (a, b, $\mathbf{c}$ ) and upper Yellow River basin (d, e, f).
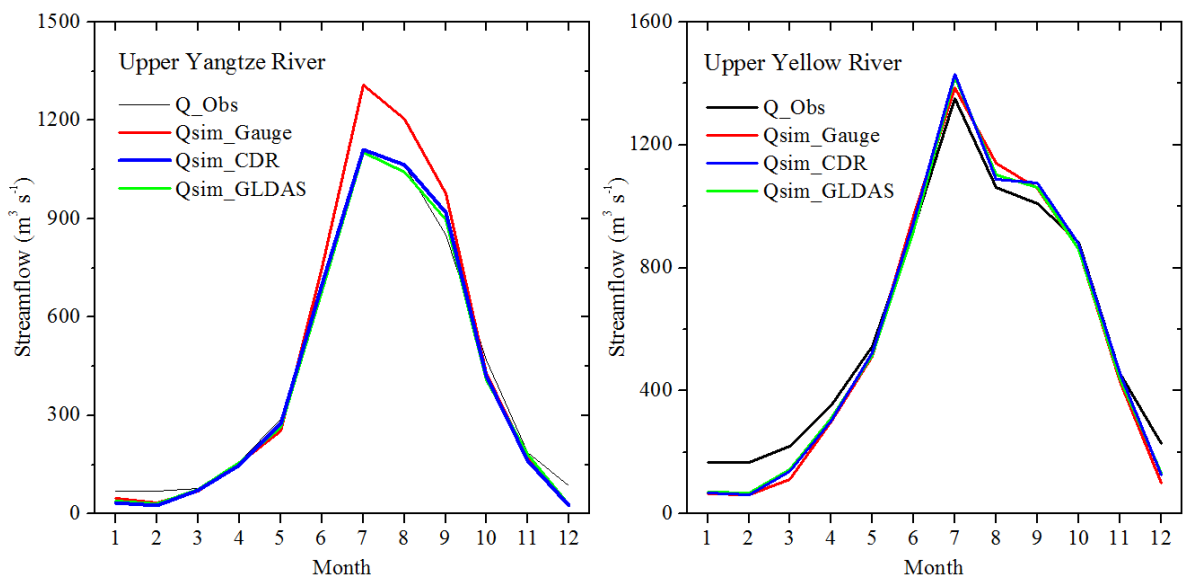

Figure 6. The comparison between the observed streamflow (black) and the simulated streamflow using ground-based precipitation (red), GLDAS precipitation (green), and PERSIANN-CDR precipitation (blue) in the upper Yangtze River basin and upper Yellow River basin.

tend to produce a smaller streamflow in the dry season with a relative bias of $-33.1,-26.9$, and $-27.6 \%$, respectively. One of the reasons that gauge-based precipitation, GLDAS precipitation, and PERSIANN-CDR precipitation generate smaller streamflow in the dry season is the lack of complex method or proper algorithm in the HIMS model to handle frozen soil. In dry season, when the amounts of precipitation and streamflow are small, streamflow melted from frozen soil can account for a significant proportion of total streamflow.
In other words, the frozen soil melt could significantly influence the streamflow simulation results. The relative high bias of observed streamflow and simulated streamflow from all the three precipitation products could be due to the lack of a proper modeling component in the HIMS hydrologic model that quantifies the frozen soil melting effects in dry season. However, the bias between simulated and observed streamflow is much smaller in the wet season, when precipitation and streamflow are relatively large and streamflow melted 
from frozen soil accounts for a limited proportion in total streamflow.

In summary, the streamflow simulated by GLDAS precipitation and PERSIANN-CDR precipitation has a good agreement with the observed streamflow in the UYZR and UYLR. The good agreement between observed streamflow and PERSIANN-CDR simulated streamflow reveals a strong streamflow simulation capability of PERSIAN-CDR product, which also gives community certain confidence in using PERSIANN-CDR product to study hydrological cycle and climate change on the Tibetan Plateau.

\section{Discussions}

\subsection{Parameter uncertainties of hydrological modeling}

In this study, model parameters are separately calibrated in terms of the highest NSE between observed streamflow and simulated streamflow driven by gauge-based precipitation, GLDAS precipitation and PERSIANN-CDR precipitation. Therefore, these parameter values are highly dependent on the precipitation inputs. When the precipitation input changes, the parameter values may change accordingly in order to match the streamflow. Table 3 shows the values of calibrated parameters separately driven by gauge-based precipitation, GLDAS precipitation, and PERSIANN-CDR precipitation in the two basins. Parameter sensitivity study of the HIMS model indicates that the HIMS model is most sensitive to parameters of the maximum soil storage capacity (SMSC) and the infiltration coefficients ( $R$ and $r$ ) (Jiang et al., 2015). In the UYLR, the parameters calibrated by the inputs of gauge-based precipitation, GLDAS precipitation, and PERSIANN-CDR precipitation generally have similar values. However, in the UYZR, SMSC, $R$, and $r$ values calibrated from gauge-based precipitation are 302.46, 1.47, and 0.78, respectively, whereas SMSC, $R$ and $r$ values calibrated from PERSIANN-CDR precipitation are 343.80, 1.71 , and 0.89 . By separately calibrating the HIMS parameters, the gauge-based precipitation, GLDAS precipitation, and PERSIANN-CDR produce different optimal parameter values. Thus, the streamflow simulation bias using gaugebased precipitation, GLDAS precipitation, and PERSIANNCDR are the joint results of parameter differences and model input bias. Correspondingly, soil moisture and evapotranspiration estimation could be different using various precipitation forcings and calibrated parameters. However, the main purpose of this study is evaluating the streamflow simulation capability of satellite-based precipitation and gauge-based precipitation as inputs to a hydrologic model over the Tibetan Plateau. Therefore, in spite of the influence of cancellation between parameter differences and precipitation bias on streamflow simulation, it does not harm the conclusion that both PERSIANN-CDR and GLDAS precipitation is able to produce a reasonably good streamflow in the two river basins on the Tibetan Plateau.

In a previous study, Tong et al. (2014) evaluated the streamflow simulation capabilities of four satellite-based precipitation products (TRMM-3B42-V7, TRMM-3B42RTV7, PERSIANN, and CMORPH) using the VIC hydrologic model in the UYZR and UYLR from 2006 to 2012. Different from the PERSIANN product that Tong et al. (2014) used, PERSIANN-CDR is a different product that provides over 33 years of daily and high-resolution precipitation with GPCP monthly information incorporated. In addition, the parameters in the VIC hydrologic model are calibrated by the input of interpolated gauge-based precipitation. The calibrated parameter values are then kept fixed when the VIC model are rerun by inputs of satellite-based precipitation datasets to evaluate the streamflow simulation capabilities of satellite-based precipitation datasets. Rerunning the hydrologic model with the fixed parameters calibrated by gaugebased precipitation partly indicates that Tong et al. (2014) assumed that the sparse gauge observations are a more reliable dataset than satellite-based precipitation datasets. However, this is a questionable assumption. As we mentioned in the introduction, not only the location of rain gauges is conditioned (relatively low elevations) but also the sparse distribution of rainfall stations over the Tibetan Plateau could bring large errors and uncertainties in regional rainfall measurement. Similar arguments are also raised by Miao et al. (2015). In this study, we rather cautiously believe that gauge-based precipitation could not be reliable, especially in the UYZR where there is only one station per $34426 \mathrm{~km}^{2}$ (nearly $1^{\circ} \times 3^{\circ}$ spatial resolution). Therefore, separately calibrating hydrologic model by the inputs of different precipitation datasets instead of using identical parameters will contribute to fairer comparisons when evaluating streamflow simulation capabilities of different precipitation datasets, although other hydrological variables such as soil moisture and evapotranspiration could be incorrectly estimated by different precipitation inputs and calibrated parameters.

\subsection{The influences of precipitation record length on streamflow simulation capability}

Besides of the uncertainties due to hydrological model calibration, another factor that influences the accuracy of streamflow simulation is the length of precipitation records used for calibration. As mentioned before, one of the advantages of PERSIANN-CDR product is the provision of more than 33 years of continuous sequences of precipitation data, which can allow for more extensive streamflow simulation in the Tibetan Plateau. In this study, comparison experiments (Fig. 7) were designed to test the influences of precipitation record length on the accuracy of streamflow simulation. In the designed experiments, we investigate the accuracy of streamflow simulation during 2008 to 2012 with two different calibration scenarios. In the first scenario, the calibration pe- 

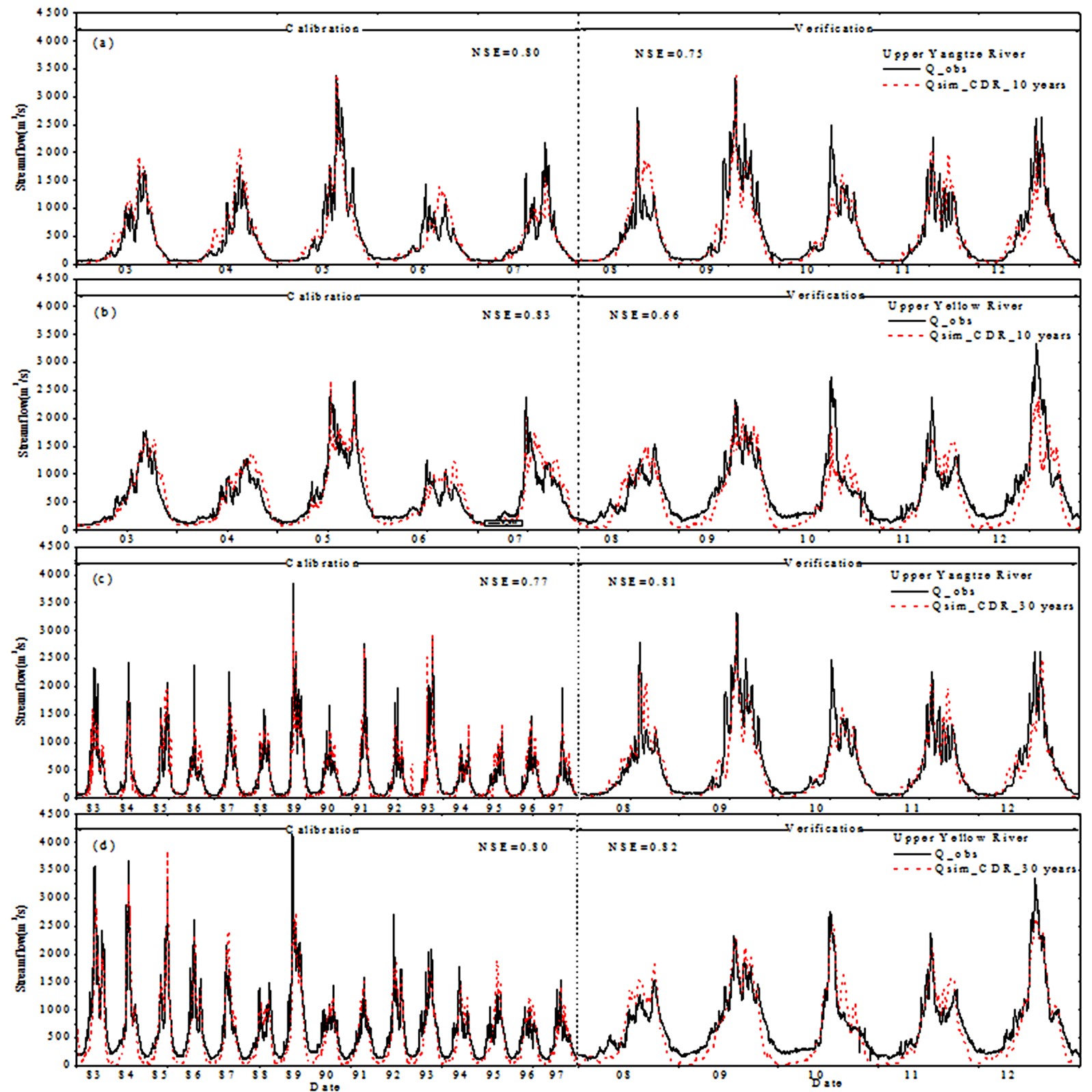

Figure 7. The simulated daily streamflow (red) forced by PERSIANN-CDR rainfall product in different scenarios and the observed daily streamflow (black) at the outlets of the upper Yangtze River basin and upper Yellow River basin. Panels (a) and (b) are the scenarios where the period 2003 to 2007 is used for calibration and 2008 to 2012 for verification. Panels (c) and (d) are the scenarios where the period 1983 to 1997 is used for calibration and 2008 to 2012 for verification.

riod is from 2003 to 2007 for both the UYZR (Fig. 7a) and the UYLR (Fig. 7b). In the second scenario (Fig. 7c and d), 15 years of data from 1983 to 1997 are used for calibration, which are longer than that in the first scenario. As it is shown in Fig. 7a and b, in the first scenario the NSE values between daily observed and simulated streamflow are 0.75 and 0.66 during the verification period (from 2008 to 2012) for the UYZR and UYLR, respectively. Comparatively, in the second scenario the NSE values during the verification period (from 2008 to 2012) are 0.81 and 0.82 for the two basins, respectively. The NSE values in the second scenario are consistently higher than that in the first scenario in the two basins. For the UYLR in the second scenario (Fig. 7d), the NSE value during the verification period is significantly greater than that in the first scenario. Figure $7 \mathrm{~b}$ also shows that the HIMS hydrological model significantly underestimates the flow peaks during the summer of 2010 and 2012 when calibrated by 5 years of data from 2003 to 2007 . The disagreement between the observed and simulated flow peaks is partly because the magnitudes of flood events during the 
calibration period are all smaller than that during the verification period and the HIMS hydrological model cannot be well trained during the calibration period. Therefore, when using a short-length precipitation data as input for a hydrological model, the accuracy of streamflow simulation could be limited, especially when precipitation data used for calibration cannot cover the flood and drought conditions of a basin. However, when the HIMS hydrological model is calibrated by the longer dataset from 1983 to 1997, as it is shown in Fig. $7 \mathrm{c}$ and d, there is a greater potential that the characteristics of extreme events can be captured by the hydrological model than using only 5 years of data from 2003 to 2007. Given the availability of long-term precipitation records (over 33 years) provided by PERSIANN-CDR product, the extreme events in the historical period could be well captured by a hydrological model. Therefore, using such a product with long-term records, the confidence of simulating streamflow over the Tibetan Plateau will correspondingly increase.

\section{Summary}

As it is compared to radar-based precipitation measurement and gauge networks, the main advantage of satellite-based precipitation estimate is the broader coverage at global scale. This allows for a comprehensive understanding of the driving force of hydrologic cycle, especially for the gauge-sparse area. To verify the accuracy of satellite-based precipitation estimate products, the comparison with ground observation is necessary. However, in a gauge-sparse area, a direct comparison on precipitation temporal and spatial variation will be questionable due to the limited gauge information. This study provides an alternative way to evaluate satellite-based precipitation products by forcing both rainfall estimates from satellite and limited gauge network into hydrological model. Given the confidence in streamflow measurements, which are more reliable and well monitored than the limited groundbased rainfall measurements, the comparison of simulated streamflow enables an indirect way to evaluate satellite-based precipitation products.

In this study, PERSIANN-CDR precipitation, GLDAS precipitation, and gauge-based precipitation have good agreements in the UYLR, whereas the three datasets have different values in the UYZR. Streamflow simulation capabilities of PERSIANN-CDR precipitation, GLDAS precipitation, and gauge-based precipitation are evaluated as the inputs of the HIMS hydrologic model in the two basins. All the three datasets have similar good performances in the UYLR, whereas PERSIANN-CDR precipitation and GLDAS precipitation have slightly better performance than gauge-based precipitation in the UYZR. Gauge-based precipitation tends to produce larger streamflow in the wet season in the UYZR. This indicates that in the UYZR, a sparse gauge network could not be fully reliable when used as the reference for streamflow simulation due to the fact that the locations of the limited gauge stations cannot be representative for measuring the precipitation patterns at the river basin scale. In addition, gauge-based precipitation, GLDAS precipitation, and PERSIANN-CDR precipitation all generate smaller streamflow in the dry season probably because of the lack of a frozen soil algorithm in HIMS model. This may bring certain uncertainties in the discharge comparisons by different precipitation inputs (Xue et al., 2013b). Further studies should be conducted to improve the frozen soil simulation of HIMS model.

Lack of rainfall gauge stations has brought a great challenge to hydrological and climate studies over the Tibetan Plateau (e.g., Yao et al., 2012; Zhang et al., 2013). Based on the demonstration in this study that PERSIANN-CDR is able to produce reasonably good streamflow in the UYZR and UYLR as compared to observed streamflow, we can speculate that the PERSIANN-CDR rainfall product has the potential to be a useful dataset and an alternative for the sparse gauge network in climate change and hydrological studies on the Tibetan Plateau considering the needs for long-term (more than 33 years) and high-resolution records.

\section{Data availability}

The GLDAS precipitation dataset is available at the website http://ldas.gsfc.nasa.gov/gldas/ (NASA, 2016). The PERSIANN-CDR rainfall dataset is available at the NOAA NCDC website (ftp://data.ncdc.noaa.gov/cdr/persiann/files/; NCDC, 2016). The streamflow data used for this paper are not publicly available due to the constraints of governmental policy in China. The data were obtained through a purchasing agreement for this study.

Acknowledgements. This research was supported by the Natural Science Foundation of China (41330529, 41571024, 41201034), the program for "Bingwei" Excellent Talents in Institute of Geographic Sciences and Natural Resources Research, CAS (project no. 2013RC202), the NOAA NCDC/Climate Data Record program (prime award NA09NES440006), and the DOE (prime award no. DE-IA0000018).

Edited by: D. Yang

Reviewed by: two anonymous referees

\section{References}

Adler, R. F., Huffman, G. J., Chang, A., Ferraro, R., Xie, P., Janowiak, J., Rudolf, B., Schneider, U., Curtis, S., Bolvin, D., Gruber, A., Susskind, J., Arkin, P., and Nelkin, E.: The version2 global precipitation climatology project (GPCP) monthly precipitation analysis (1979-present), J. Hydrometeorol., 4, 11471167, 2003. 
Artan, G., Gadain, H., Smith, J. L., Bandaragoda, C. J., and Verdin, J. P.: Adequacy of satellite derived rainfall data for stream flow modeling, Nat. Hazards, 43, 167-185, 2007.

Ashouri, H., Hsu, K., Sorooshian, S., Braithwaite, D., Knapp, K. R., Cecil, L. D., Nelson, B. R., and Prat, O. P.: PERSIANN-CDR: Daily precipitation climate data record from multisatellite observations for hydrological and climate studies, B. Am. Meteorol. Soc., 96, 69-83, doi:10.1175/BAMS-D-13-00068.1, 2015.

Bitew, M. M., Gebremichael, M., Ghebremichael, L. T., and Bayissa, Y. A.: Evaluation of high-resolution satellite rainfall products through streamflow simulation in a hydrological modeling of a small mountainous watershed in Ethiopia, J. Hydrometeorol., 13, 338-350, 2012.

Duan, Q., Sorooshian, S., and Gupta, V.: Effective and efficient global optimization for conceptual rainfall-runoff models, Water Resour. Res., 28, 1015-1031, 1992.

Franchini, M. and Lamberti, P.: A flood routing Muskingum type simulation and forecasting model based on level data alone, Water Resour. Res., 30, 2183-2196, 1994.

Garcia, M., Peters-Lidard, C. D., and Goodrich, D. C.: Spatial interpolation of precipitation in a dense gauge network for monsoon storm events in the southwestern United States, Water Resour. Res., 44, W05S13, doi:10.1029/2006WR005788, 2008.

Gottschalck, J., Meng, J., Rodell, M., and Houser, P.: Analysis of multiple precipitation products and preliminary assessment of their impact on global land data assimilation system land surface states, J. Hydrometeorol., 6, 573-598, doi:10.1175/JHM437.1, 2005.

Hargreaves, G. H. and Samani, Z. A.: Reference crop evapotranspiration from temperature, Appl. Eng. Agric., 1, 96-99, 1985.

Hock, R.: Temperature index melt modelling in mountain areas, J. Hydrol., 282, 104-115, doi:10.1016/S0022-1694(03)00257-9, 2003.

Huffman, G. J., Adler, R. F., Morrissey, M. M., Bolvin, D. T., Curtis, S., Joyce, R., McGavock, B., and Susskind, J.: Global Precipitation at One-Degree-Daily Resolution from Multisatellite Observations, J. Hydrometeorol., 2, 36-50, 2001.

Jiang, Y., Liu, C., and Li, X.: Hydrological impacts of climate change simulated by HIMS models in the Luanhe River Basin, North China, Water Resour. Manag., 29, 1365-1384, 2015.

Joyce, R. J., Janowiak, J. E., Arkin, P. A., and Xie, P.: CMORPH: a method that produces global precipitation estimates from passive microwave and infrared data at high spatial and temporal resolution, J. Hydrometeorol., 5, 487-503, 2004.

Kidd, C. and Levizzani, V.: Status of satellite precipitation retrievals, Hydrol. Earth Syst. Sci., 15, 1109-1116, doi:10.5194/hess-15-1109-2011, 2011.

Knapp, K. R.: Scientific data stewardship of International Satellite Cloud Climatology Project B1 global geostationary observations, J. Appl. Remote Sens., 2, 023548, doi:10.1117/1.3043461, 2008.

Liu, C. M., Zheng, H. X., and Wang, Z. G.: Distributed Simulation of Catchment Water Cycle, Yellow River Conservancy Press, Zhengzhou, China, 2006.

Liu, C. M., Wang, Z. G., Zheng, H. X., Zhang, L., and Wu, X. F.: Development andapplication of HIMS system, Sci. China, 38, 350-360, 2008.

Liu, C. M., Wang, Z. G., Yang, S. T., and Zheng, H. X.: Research progress of water cycle integrated simulation system (HIMS), Water Resour. Dev. Res., 8, 5-15, 2010a (in Chinese).
Liu, C. M., Zheng, H. X., Wang, Z. G., and Yang, S. T.: Multi-Scale integrated simulation of hydrological processes using HIMS with verified case studies, J. Beijing Norm. Univ. Nat. Sci., 46, 268273, 2010b (in Chinese).

Ly, S., Charles, C., and Degré, A.: Geostatistical interpolation of daily rainfall at catchment scale: the use of several variogram models in the Ourthe and Ambleve catchments, Belgium, Hydrol. Earth Syst. Sci., 15, 2259-2274, doi:10.5194/hess-15-22592011, 2011.

Miao, C., Ni, J., and Borthwick, A. G.: Recent changes of water discharge and sediment load in the Yellow River basin, China, Prog. Phys. Geog., 34, 541-561, 2010.

Miao, C., Ni, J., Borthwick, A. G., and Yang, L.: A preliminary estimate of human and natural contributions to the changes in water discharge and sediment load in the Yellow River, Global Planet. Change, 76, 196-205, 2011.

Miao, C., Ashouri, H., Hsu, K.-L., Sorooshian, S., and Duan, Q.: Evaluation of the PERSIANN-CDR daily rainfall estimates in capturing the behavior of extreme precipitation events over China, J. Hydrometeorol., 16, 1387-1396, doi:10.1175/JHM-D14-0174.1, 2015.

Nalder, I. A. and Wein, R. W.: Spatial interpolation of climatic normals: test of a new method in the Canadian boreal forest, Agr. Forest Meteorol., 92, 211-225, 1998.

Nash, J. and Sutcliffe, J.: River flow forecasting through conceptual models Part I - A discussion of principles, J. Hydrol., 10, 282290, doi:10.1016/0022-1694(70)90255-6, 1970.

National Aeronautics and Space Administration (NASA): GLDAS precipitation, available at: http://ldas.gsfc.nasa.gov/gldas/, last access: 20 September 2016.

National Climatic Data Center (NCDC): PERSIANN-CDR rainfall, National Oceanic and Atmospheric Administration (NOAA), available at: ftp://data.ncdc.noaa.gov/cdr/persiann/files/, last access: 10 April 2016.

Rodell, M., Houser, P. R., Jambor, U. E. A., and Gottschalck, J.: The global land data assimilation system, B. Am. Meteorol. Soc., 85, 381-394, doi:10.1175/BAMS-85-3-381, 2004.

Sheffield, J., Wood, E. F., Chaney, N., Guan, K., Sadri, S., Yuan, X., Olang, L., Amani, A., Ali, A., and Demuth, S.: A drought monitoring and forecasting system for sub-Sahara African water resources and food security, B. Am. Meteorol. Soc., 95, 861-882, doi:10.1175/BAMS-D-12-00124.1, 2014.

Sorooshian, S., Hsu, K.-L., Gao, X., Gupta, H. V., Imam, B., and Braithwaite, D.: Evaluation of PERSIANN system satellitebased estimates of tropical rainfall, B. Am. Meteorol. Soc., 81, 2035-2046, 2000.

Sorooshian, S., AghaKouchak, A., Arkin, P., Eylander, J., FoufoulaGeorgiou, E., Harmon, R., Hendrickx, J. M. H., Imam, B., Kuligowski, R., Skahill, B., and Skofronick-Jackson, G.: Advancing the remote sensing of precipitation, B. Am. Meteorol. Soc., 92, 1271-1272, doi:10.1175/BAMS-D-11-00116.1, 2011.

Su, F., Gao, H., Huffman, G. J., and Lettenmaier, D. P.: Potential utility of the real time TMPA-RT precipitation estimates in Streamflow prediction, J. Hydrometeorol., 12, 444-455, 2011.

Thom, H. C. S.: A note on the gamma distribution, Mon. Weather Rev., 86, 117-122, doi:10.1175/15200493(1958)086<0117:ANOTGD>2.0.CO;2, 1958.

Tong, K., Su, F., Yang, D., and Hao, Z.: Evaluation of satellite precipitation retrievals and their potential utilities in hydrologic 
modeling over the Tibetan Plateau, J. Hydrol., 519, 423-437, doi:10.1016/j.jhydrol.2014.07.044, 2014.

Turk, F. J. and Miller, S. D.: Toward improved characterization of remotely sensed precipitation regimes with MODIS/AMSRE blended data techniques, IEEE T. Geosci. Remote, 43, 1059$1069,2005$.

Wang, F., Wang, L., Koike, T., Zhou, H., Yang, K., Wang, A., and Li, W.: Evaluation and application of a fine-resolution global data set in a semiarid mesoscale river basin with a distributed biosphere hydrological model, J. Geophys. Res.-Atmos., 116, D21108, doi:10.1029/2011JD015990, 2011.

Xie, P. P., Janowiak, J. E., Arkin, P. A., Adler, R., Gruber, A., Ferraro, R., Huffman, G. J., and Curtis, S.: GPCP Pentad precipitation analyses: An experimental dataset based on gauge observations and satellite estimates, J. Climate, 16, 2197-2214, doi:10.1175/2769.1, 2003.

Xue, B. L., Wang, L., Li, X., Yang, K., Chen, D., and Sun, L.: Evaluation of evapotranspiration estimates for two river basins on the Tibetan Plateau by a water balance method, J. Hydrol., 492, 290 297, 2013a.

Xue, B. L., Wang, L., Yang, K., Tian, L., Qin, J., Chen, Y., Zhao, L., Ma, Y., Koike, T., Hu, Z., and Li, X.-P.: Modeling the land surface water and energy cycle of a mesoscale watershed in the central Tibetan Plateau with a distributed hydrological model, J. Geophys. Res.-Atmos., 118, 8857-8868, doi:10.1002/jgrd.50696, 2013b.

Yang, T., Gao, X., Sellars, S. L., and Sorooshian, S.: Improving the multi-objective evolutionary optimization algorithm for hydropower reservoir operations in the California OrovilleThermalito complex, Environ. Modell. Softw., 69, 262-279, 2015.
Yao, T. D., Thompson, L., Yang, W., Yu, W., Gao, Y., Guo, X., Yang, X., Duan, K., Zhao, H., Xu, B., Pu, J., Lu, A., Xiang, Y., Kattel, D. B., and Joswiak, D.: Different glacier status with atmospheric circulations in Tibetan Plateau and surroundings, Nat. Clim. Change, 2, 663-667, 2012.

Yilmaz, K. K., Hogue, T. S., Hsu, K.-L., and Sorooshian, S.: Intercomparison of rain gauge, radar, and satellite-based precipitation estimates with emphasis on hydrologic forecasting, J. Hydrometeorol., 6, 497-517, 2005.

Yong, B., Ren, L., Hong, Y., Wang, J., Gourley, J., Jiang, S., Chen, $\mathrm{X}$., and Wang, W.: Assessment of evolving TRMM-based multisatellite real-time precipitation estimation methods and their impacts on hydrologic prediction in a high latitude basin, J. Geophys. Res., 117, D09108, doi:10.1029/2011JD017069, 2012.

Zhang, L., Su, F., Yang, D., Hao, Z., and Tong, K.: Discharge regime and simulation for the upstream of major rivers over Tibetan Plateau, J. Geophys. Res., 118, 8500-8518, doi:10.1002/jgrd.50665, 2013.

Zhang, X. and Tang, Q.: Combining satellite precipitation and longterm ground observations for hydrological monitoring in China, J. Geophys. Res., 120, 6426-6443, doi:10.1002/2015JD023400, 2015.

Zhang, Y., Liu, S., and Ding, Y.: Observed degree-day factors and their spatial variation on glaciers in western China, Ann. Glaciol., 43, 301-306, 2006.

Zhu, Q., Xuan, W., Liu, L., and Xu, Y. P.: Evaluation and hydrological application of precipitation estimates derived from PERSIANN-CDR, TRMM 3B42V7, and NCEP-CFSR over humid regions in China, Hydrol. Process., 30, 3061-3083, doi:10.1002/hyp.10846, 2016. 